\title{
Dual Sensory Impairment among Community Dwelling Rural Elderly: Concern for Rehabilitation
}

\author{
Deepthi Ramamurthy, ${ }^{1}$ Arvind Kasthuri, ${ }^{2}$ and Rekha Sonavane ${ }^{3}$ \\ ${ }^{1}$ Department of Community Medicine, ESIC-MC \& PGIMSR, Rajajinagar, Bangalore 560010, India \\ ${ }^{2}$ Department of Community Health, St. John's Medical College, Bangalore 560034, India \\ ${ }^{3}$ Department of Community Medicine, Al-Ameen Medical College, Bijapur 586108, India
}

Correspondence should be addressed to Deepthi Ramamurthy; drdeepthikiran@gmail.com

Received 30 September 2013; Revised 4 December 2013; Accepted 8 December 2013; Published 29 January 2014

Academic Editor: Shunichiro Shinagawa

Copyright (C) 2014 Deepthi Ramamurthy et al. This is an open access article distributed under the Creative Commons Attribution License, which permits unrestricted use, distribution, and reproduction in any medium, provided the original work is properly cited.

\begin{abstract}
Background. There is an increase in dual sensory impairment (DSI) (hearing and visual) with increase in elderly population. Most causes of DSI among elderly are treatable. This study determines the prevalence and characteristics of dual sensory impairment among elderly of a rural community. Material and Methods. A cross-sectional study conducted among 175 rural elderly. Visual acuity for distant vision was measured using Snellen E chart. Hearing ability was measured using pure tone audiometry. Results. The prevalence of hearing impairment was $72 \%$ and that of visual impairment was $48 \%$. The overall prevalence of DSI among the study subjects was $17.7 \%$ and $32.6 \%$ depending on whether traditional pure tone average or high-frequency pure tone average was used to define moderate or worse degree of hearing impairment. DSI prevalence increased significantly with increase in age. DSI was higher among widow/ers and illiterates, who did not have any source of income and those who were financially dependent on others compared to their counter groups. Conclusion. Prevalence of DSI is high among community dwelling rural Indian elderly. Individuals with DSI produce unique challenges in rehabilitation. A team approach at primary health care level is necessary to diagnose and rehabilitate elderly thereby enabling them to easily lead an independent life.
\end{abstract}

\section{Introduction}

Hearing and visual ability are key aspects of functioning among the elderly. Hearing and visual impairments among elderly have been studied extensively as single sensory impairments, but dual sensory impairment (DSI) among them is less well understood. Studies have proven that individuals with DSI have more difficulty in performing activities of daily living and instrumental activities of daily living [13] compared to individuals with single sensory impairment. In comparison with a single sensory impairment, DSI is associated with more depressive symptoms [4], lower health related quality of life [5], and also increased risk of mortality [6].

Older age is a well known risk factor for sensory impairments. Elderly proportion in India according to 2011 census is $8.1 \%$ and is expected to rise to $17 \%$ by the year 2025
$[7,8]$. The special features of Indian elderly population which is a challenge are a majority ( $80 \%)$ of them being in the rural areas, large percentage $(30 \%)$ being in below poverty line, feminization of the elderly population, and increase in the number of the oldest age group ( $\geq 80$ years) $[8,9]$. Geriatric medical care differs from usual medical care in shifting the focus to preservation of function and improving the quality of life rather than treating and curing specific diseases. Increasing elderly population will eventually lead to increase in the prevalence of DSI in India.

Various studies demonstrate that the prevalence rate of DSI among elderly ranges from 6.5 to 35.0 percent $[1,4-$ $6,10-14]$. There is complexity associated with defining and understanding DSI as it is determined by the definitions for the respective single sensory impairments. Most studies are from developed countries, are hospital based, and use traditional pure tone average (PTA) to classify hearing 
impairment. The majority of studies have used self-report of hearing and visual loss to arrive at prevalence of DSI as there are difficulties in performing objective assessment using pure tone audiometry and visual acuity is evaluated for diagnosing DSI $[1,6,10,11]$. Most studies use traditional PTA of the air conduction thresholds at 500, 1000 and $2000 \mathrm{~Hz}$ to assess hearing impairment as it correlates with the auditory threshold for speech stimuli $[15,16]$. High-frequency PTA (HFPTA) including the thresholds at 4000 and $8000 \mathrm{~Hz}$, which has a stronger relationship in the understanding of speech signals presented in background noise, is not considered in many studies [17-19].

Individuals with DSI produce unique challenges in rehabilitation. Often individuals with hearing impairment depend on visual cues for communication and use their amplification devices. Similarly individuals with visual impairment need auditory cues to assist with communication and ambulation. Effective rehabilitation of individuals with DSI may be hindered as alternative sensory input cannot be used in a compensatory fashion. Generally rehabilitation of hearing and vision impairments is accomplished separately by audiologists and ophthalmologists, respectively, with little interaction between them for individuals with DSI. Comprehension of the magnitude and characteristics of DSI among Indian elderly is important in formulating public policies in terms of surveillance, research, and intervention design. Field based objective assessment of DSI will provide true estimates which will help in establishing a community-based rehabilitation programme for elderly. Considering the abovementioned need this study was conducted with the objective of estimating prevalence of DSI among community dwelling rural elderly and describing its characteristics.

\section{Material and Methods}

It was a community-based cross-sectional study, carried out at two villages of Bangalore District, Karnataka. All persons above the age of 60 years who are residents in these two were included in the study. Persons not found even after three attempts to contact them at their home or workplace and moribund bed ridden elderly were excluded from the study. Institutional ethical board approval has been obtained for this study.

There were a total of 257 elderly in two villages, of which 175 consented to participate in the study. A house-to-house survey was conducted to identify elderly persons. Informed consent was taken and a pretested questionnaire was administered by interviewer to the subjects. Demographic details, educational status, living arrangements, occupation, source of income, and financial dependence were collected. "Standard of Living Index" was used to classify socioeconomic status of the families as low, middle, and high socioeconomic class [20]. Financial dependence was assessed by asking whether the elderly person was financially dependent on their family members, either partially or completely.

Hearing assessment was done by unaided pure tone audiometry. Pure tone audiometry was done by trained workers in silent rooms away from the road. Care was taken so that there was no external noise by closing all the doors and windows of the room and requesting the people around the room to maintain silence until the procedure was completed. Ambient noise was measured at the beginning of audiometry using decibelometer and ensured that it was below $30 \mathrm{~dB}$ [21]. Measured hearing loss was determined using pure tone audiometry, intensity of sound was measured in decibels, and both degree and type of deafness were assessed. Air conduction thresholds were measured for tones of 250, 500, 1000, 2000, 4000, and $8000 \mathrm{~Hz}$. Bone conduction thresholds were measured for 250, 500, 1000, 2000, and $4000 \mathrm{~Hz}$. Hearing impairment was measured by calculating traditional PTA of the air conduction thresholds at 500, 1000, and $2000 \mathrm{~Hz}$. High-frequency pure tone average (HFPTA) of $4 \mathrm{KHz}$ and $8 \mathrm{KHz}$ was also calculated to evaluate high frequency hearing loss. Both the readings were considered for the better ear to grade the hearing impairment. The PTAs used to describe the degree of hearing impairment are defined as follows: (1) normal, $<25 \mathrm{~dB}$ hearing level (dB HL), (2) mild, 25 to $40 \mathrm{~dB}$ $\mathrm{HL},(3)$ moderate, 41 to $55 \mathrm{~dB} \mathrm{HL}$, (4) severe, 56 to $70 \mathrm{~dB} \mathrm{HL}$ and (5) profound, $>70 \mathrm{~dB} \mathrm{HL}$.

Vision assessment was done by checking distant visual acuity. Distant vision was assessed by Snellen E chart using standard techniques. If the elderly person failed to read the topmost line (6/60), then finger counting was checked up to one meter by a decrement of one meter. If the elderly still failed to respond, then hand movements close to eyes, perception of light, and projection of rays were assessed. If the visual acuity was less than $6 / 18$ in the better eye with best available correction, then such people were considered as visually impaired. Elderly with visual acuity between 6/18 and 6/60 were classified as having low vision and those with visual acuity less than or equal to $6 / 60$ in the better eye with best available correction were considered blind according to the National Programme for Control of Blindness definition.

As there is no standard definition for DSI, we formulated an operational definition using previously described categories of sensory impairment. The visual impairment component of DSI was defined as best corrected visual acuity of worse than $6 / 18$ in the better eye, whereas hearing impairment definitions was based on PTA of $>40 \mathrm{~dB} \mathrm{HL}$ or worse in the better ear which was chosen because individuals with this degree of hearing impairment would likely have considerable listening difficulties in most situations.

Prevalence was estimated by calculating the proportion of elderly with hearing impairment alone, with vision impairment alone, and with DSI for each age group. A test of significance of difference in the prevalence across the age groups was performed with chi square test. Pearson's correlation coefficient was calculated between age in years and level of hearing in decibels among the study population.

\section{Results}

Totally 175 elderly consented to participate in the study from two villages. Since DSI definition was derived from a combination of single sensory impairments, the prevalence of 
TABLE 1: Mean \pm standard deviation pure tone thresholds, PTA, and HFPTA in decibels hearing levels in three age groups of elderly.

\begin{tabular}{|c|c|c|c|c|c|c|c|c|c|c|}
\hline \multirow{2}{*}{ Group } & \multirow{2}{*}{ Age (yrs) } & \multirow{2}{*}{$N$} & \multicolumn{6}{|c|}{ Frequency $(\mathrm{Hz})$ mean $\pm \mathrm{SD}$} & \multirow{2}{*}{ PTA } & \multirow{2}{*}{ HFPTA } \\
\hline & & & 250 & 500 & 1000 & 2000 & 4000 & 8000 & & \\
\hline Young old & $63.4 \pm 4.1$ & 82 & $28.6 \pm 10.4$ & $29.1 \pm 10.6$ & $26.7 \pm 10.5$ & $26.8 \pm 11.7$ & $33.0 \pm 17.0$ & $39.4 \pm 19.1$ & $29.6 \pm 11.6$ & $36.6 \pm 16.9$ \\
\hline Old old & $71.8 \pm 2.5$ & 56 & $32.3 \pm 13.6$ & $33.5 \pm 14.1$ & $33.0 \pm 13.3$ & $33.7 \pm 15.7$ & $41.1 \pm 18.6$ & $47.9 \pm 18.9$ & $35.8 \pm 14.1$ & $44.8 \pm 17.9$ \\
\hline Oldest old & $83.5 \pm 4.7$ & 37 & $40.9 \pm 13.1$ & $41.8 \pm 12.9$ & $38.6 \pm 15.3$ & $40.9 \pm 15.8$ & $50.7 \pm 16.3$ & $61.2 \pm 14.7$ & $43.8 \pm 14.1$ & $56.2 \pm 13.3$ \\
\hline
\end{tabular}

TABLE 2: Degree of hearing impairment based traditional PTA and HFPTA among elderly $(N=175)$.

\begin{tabular}{|c|c|c|c|c|c|}
\hline \multirow{2}{*}{ Degree of hearing impairment } & \multirow{2}{*}{ Corresponding hearing levels } & \multicolumn{2}{|c|}{ PTA } & \multicolumn{2}{|c|}{ HFPTA } \\
\hline & & $N$ & $\%(95 \% \mathrm{CI})$ & $N$ & $\%(95 \% \mathrm{CI})$ \\
\hline Normal & $<25 \mathrm{~dB}$ & 49 & $28.0(21.9-35.1)$ & 34 & $19.4(14.2-25.9)$ \\
\hline Mild & $25-40 \mathrm{~dB}$ & 82 & $46.9(39.6-54.2)$ & 46 & $26.3(20.3-33.3)$ \\
\hline Moderate & $41-55 \mathrm{~dB}$ & 23 & $13.1(8.9-18.9)$ & 45 & $25.7(19.8-32.7)$ \\
\hline Severe & $56-70 \mathrm{~dB}$ & 20 & $11.4(7.5-17.0)$ & 41 & $23.4(17.8-30.2)$ \\
\hline Profound & $>71 \mathrm{~dB}$ & 1 & $0.6(0.1-3.1)$ & 9 & $5.1(2.7-9.5)$ \\
\hline
\end{tabular}

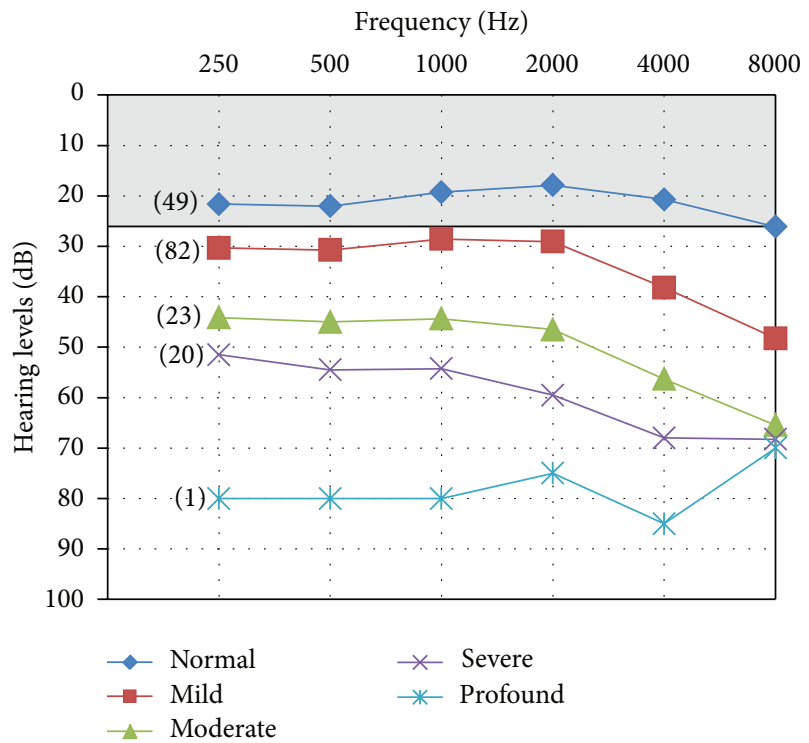

FIGURE 1: Mean audiogram of better ear is illustrated for each degree of hearing impairment category, which was based on traditional PTA.

hearing impairment, visual impairment, and DSI is presented separately.

3.1. Hearing Impairment. Old age has been categorized into young old (60-69 years), old old (70-79 years), and oldest old ( $\geq 80$ years). The mean pure tone, air conduction thresholds in the better ear for each age group are listed in Table 1, along with the mean values for the PTA and HFPTA for the better ear. It shows that mean PTA and mean HFPTA steadily increased at each frequency with increase in age. With increase in age there is a statistically significant increase in pure tone average $(r=0.37, P<0.001)$ and highfrequency pure tone average $(r=0.41, P<0.001)$.
Table 2 lists the percentage of elderly and 95\% confidence interval (CI) for each hearing impairment category based on traditional PTA and HFPTA. Most of the elderly (46.9\%) have mild hearing impairment. Overall, 44 elderly, that is, $25.1 \%$ of the elderly, have moderate or worse degree of hearing impairment. Among these only two elderly were using hearing aids regularly. The number of elderly with high frequency hearing impairment is $80.6 \%$ and elderly with moderate or worse degree of hearing impairment rised to $54.2 \%$. There were nine (5.1\%) elderly with profound hearing impairment in this category. Some elderly defined as having normal hearing under traditional PTA were classified into having hearing impairment when HFPTA was considered.

Mean audiogram based on traditional PTA for each degree of hearing impairment is represented in Figure 1. Normal hearing sensitivity is depicted by the shaded region in Figure 1 with thresholds $<25 \mathrm{~dB} H \mathrm{HL}$ at each frequency. The numbers in the parentheses to the left of each function indicate the number of participants who were defined as having the corresponding category of hearing impairment. Based on the traditional PTA, it suggests that the majority of elders had mild to moderate hearing impairments and few of them had severe to profound impairments. We can observe that people with mild to moderate hearing impairment on traditional PTA are showing moderate to severe hearing impairment at 4000 and $8000 \mathrm{~Hz}$. These elderly may have difficulty in understanding conversation when there is a background noise or conversing on the telephone. While classifying hearing impairment among elderly, it is better to consider traditional PTA and HFPTA.

3.2. Visual Impairment. The participants were classified into three vision categories based on their best available distance visual acuity in the better eye using Snellen E chart: (1) normal vision $\leq 6 / 18$ (2) low vision $>6 / 18$ to $<6 / 60$, and (3) blindness $\geq 6 / 60$. The prevalence rate and its $95 \%$ confidence interval of each of the three vision categories for each age group are listed in Table 3. Nearly half of 
TABle 3: Prevalence of visual impairment based on the National Programme of Control of Blindness for elderly in three age groups.

\begin{tabular}{lcccc}
\hline Vision & Young old $(N=82)$ & Old old $(N=56)$ & Oldest old $(N=37)$ & Total $(N=175)$ \\
\hline Normal vision \% (95\% CI) & $68.3(57.6-77.3)$ & $41.1(29.2-54.1)$ & $32.4(19.6-48.5)$ & $52.0(44.6-59.3)$ \\
Low vision \% (95\% CI) & $23.2(15.4-33.4)$ & $42.9(30.8-55.9)$ & $51.4(35.9-66.5)$ & $35.5(28.7-42.8)$ \\
Blindness \% (95\% CI) & $8.5(4.2-16.6)$ & $16.1(8.7-9.5)$ & $16.2(7.6-31.1)$ & $12.5(8.4-18.3)$ \\
\hline
\end{tabular}

TABLE 4: Prevalence of DSI among elderly as determined by traditional PTA and HFPTA.

\begin{tabular}{|c|c|c|c|c|}
\hline \multirow{3}{*}{ Variables } & \multicolumn{4}{|c|}{ DSI } \\
\hline & \multicolumn{2}{|c|}{ PTA } & \multicolumn{2}{|c|}{ HFPTA } \\
\hline & $N$ & $\%(95 \% \mathrm{CI})$ & $N$ & $\%(95 \% \mathrm{CI})$ \\
\hline \multicolumn{5}{|l|}{ Gender } \\
\hline Male $(N=86)$ & 16 & $18.6(11.8-28.1)$ & 30 & $34.9(25.6-45.4)$ \\
\hline Female $(N=89)$ & 15 & $16.8(10.5-26.0)$ & 27 & $30.3(27.8-68.2)$ \\
\hline \multicolumn{5}{|l|}{ Age groups } \\
\hline Young old $(N=82)$ & 5 & $6.1(2.6-13.5)$ & 11 & $13.4(7.7-22.4)$ \\
\hline Old old $(N=56)$ & 10 & $17.8(10.0-29.8)$ & 23 & $41.1(29.2-54.1)$ \\
\hline Oldest old $(N=37)$ & 16 & $43.2(28.7-59.1)$ & 23 & $62.2(46.1-75.9)$ \\
\hline \multicolumn{5}{|l|}{ Socioeconomic status } \\
\hline $\operatorname{High}(N=19)$ & 4 & $21.1(8.5-43.3)$ & 7 & $36.8(19.2-59.0)$ \\
\hline $\operatorname{Medium}(N=41)$ & 8 & $19.5(10.2-34.0)$ & 12 & $29.3(17.6-44.5)$ \\
\hline Low socioeconomic status $(N=115)$ & 19 & $16.5(10.8-24.4)$ & 38 & $33(25.1-42.1)$ \\
\hline \multicolumn{5}{|l|}{ Marital status } \\
\hline Unmarried $(N=2)$ & 0 & 0 & 0 & 0 \\
\hline Married/living with spouse $(N=103)$ & 13 & $12.6(7.5-20.4)$ & 26 & $25.2(17.9-34.4)$ \\
\hline Widow $(\mathrm{er})(N=70)$ & 18 & $25.7(16.9-37.0)$ & 31 & $44.3(33.2-55.9)$ \\
\hline \multicolumn{5}{|l|}{ Educational status } \\
\hline Illiterates $(N=127)$ & 25 & $19.7(13.7-27.4)$ & 48 & $37.8(29.8-46.5)$ \\
\hline Literates $(N=48)$ & 6 & $12.5(5.9-24.7)$ & 9 & $18.7(10.2-31.9)$ \\
\hline \multicolumn{5}{|l|}{ Source of income } \\
\hline Source of income present $(N=93)$ & 16 & $17.2(10.9-26.1)$ & 25 & $26.9(18.9-36.7)$ \\
\hline Source of income absent $(N=82)$ & 15 & $18.3(11.4-28.0)$ & 32 & $39(29.2-49.8)$ \\
\hline \multicolumn{5}{|l|}{ Financial dependence } \\
\hline Financial independence $(N=47)$ & 7 & $14.9(7.4-27.7)$ & 11 & $23.4(13.6-37.2)$ \\
\hline Partially dependent $(N=34)$ & 7 & $20.6(10.3-36.8)$ & 11 & $32.4(19.1-49.2)$ \\
\hline Completely dependent $(N=94)$ & 17 & $18.1(11.6-27.1)$ & 35 & $37.2(28.1-47.3)$ \\
\hline $\operatorname{Total}(N=175)$ & 31 & $17.7(12.8-24.0)$ & 57 & $32.6(26.1-39.8)$ \\
\hline
\end{tabular}

the elderly, that is, $48 \%$, are visually impaired, $35.5 \%$ having low vision and $12.6 \%$ having blindness across all age groups. Finally, the data indicate a significant increase in the prevalence of low vision and blindness with increasing age $\left(\chi^{2}=17.2, d f=4\right.$, and $\left.P=0.002\right)$.

3.3. Dual Sensory Impairment. DSI prevalence with traditional PTA and HFPTA is shown in Table 4. Prevalence of DSI is $17.7 \%$ when PTA was considered and it increased to $32.6 \%$ when HFPTA was considered. There was a significant increase in the prevalence of DSI with age both when traditional PTA $\left(\chi^{2}=30.5, d f=4\right.$, and $\left.P<0.001\right)$ and HFPTA $\left(\chi^{2}=17.4, d f=4\right.$, and $\left.P=0.001\right)$ are considered.
DSI prevalence is slightly more among males compared to females. It is observed that DSI prevalence is significantly high among widows compared to elderly who are married and living with their spouse considering traditional PTA $\left(\chi^{2}=4.86, d f=1\right.$, and $\left.P=0.03\right)$ and HFPTA $\left(\chi^{2}=\right.$ 6.84, $d f=1$, and $P=0.009)$. DSI prevalence was higher among illiterates and elderly who did not have any source of income than compared to their counter groups.

\section{Discussion}

This study shows the prevalence and characteristics of DSI among community dwelling rural elderly. The prevalence of 
hearing impairment was $72 \%$ and that of visual impairment was $48 \%$. The overall prevalence of DSI among the study subjects, $17.7 \%$ or $32.6 \%$ depending on PTA or HFPTA, was used to define moderate or worse degree of hearing impairment.

A direct comparison of DSI prevalence rates between the present study and any other study is difficult owing to variability in age groups, DSI definitions, and place of study. Campbell et al. [10] and Chou and Chi [11] in their studies among elderly reported lower DSI prevalence of $8.6 \%$ and $6.5 \%$, respectively, as they have used self-reported data for assessing hearing and visual impairment. Lam et al. [6] have estimated a very low DSI prevalence of $1.3 \%$ as the study population included all adults over 18 years of age. Brennan et al. [1] reported $21 \%$ of DSI prevalence among people aged more than 70 years using self-reported data which is close to the prevalence of our study. This may be because the study was from a large community-based population. Chia et al. [5] used traditional PTA and visual acuity to estimate a low DSI prevalence of $6 \%$. Lieberman et al. [13] in their study estimated a higher DSI prevalence of $35 \%$ by using PTA and visual acuity as the study subjects are institutionalized population. Keller et al. [2] and Lupsakko et al. [4] used whisper test and visual acuity checking to estimate DSI prevalence of $13 \%$ and $7 \%$, respectively. Lupsakko used visual acuity of $<20 / 60$ near or distance best corrected binocular vision. Smith et al. [12] estimated a prevalence of DSI among veterans aged above 44 years at an institution to be 5.0 or 7.4 percent, depending on whether the traditional PTA or the HFPTA was used to define hearing impairment. Different prevalence rates signify that DSI is difficult to understand and warrants a uniform definition which has to be formulated for better comparison.

High-frequency PTA has been shown to have a stronger relationship to the understanding of speech signals presented in background noise than traditional PTA [19]. Smith et al. in their study have demonstrated that classifying hearing impairment with the HFPTA is more consistent with the functional hearing status than traditional PTA similar to this study [12]. Hence it is better to use PTA based on pure tone thresholds at 1000,2000 , and $4000 \mathrm{~Hz}$ than just use traditional PTA for assessing hearing impairment degree.

Prevalence of visual impairment in our study was $48.0 \%$ and that of blind was $12.5 \%$. This prevalence is very high compared to the prevalence in the United States [22] which is $9.3 \%$ and that of Rotterdam study [23]. In a cross-sectional study done in a rural population of South India [24], 11.4\% of the elderly people were blind which is similar to our study. This may be because of well developed programmes, good educational levels, and awareness regarding health problems in developed countries compared to that of India.

Hearing and vision impairments may not manifest as disabilities leading to misdiagnosis or misunderstanding. An older person with vision impairment may appear timid, hesitant, or confused, especially when confronted with a new situation [25]. Similarly, older people with hearing impairment may miss the nuances of conversation and appear confused, creating unjustified impatience on the part of those with whom they are speaking [26]. These experiences may lead to isolation, disappointment, and frustration [27]. Sensory decline may compromise one's ability to hear whispered conversation or side remarks, write notes, read the newspaper, and recognize facial expressions. DSI rehabilitation is necessary as studies have proven that correction of visual and hearing deficits improves quality of life and is also associated with reduced risk of mortality [28-30].

There was increase in the prevalence of visual impairment, hearing impairment, and DSI with increase in age. This finding is consistent with the results of study conducted by Smith et al. [12]. Hearing aid use is much higher in studies done in western countries as compared to our study $[10,12]$. Since most DSI belong to older population, it adds on to the difficulty in rehabilitation. DSI prevalence among elderly living alone was significantly higher compared to the ones who were married and living with their spouses. This has great importance as living arrangements are determined by various factors such as marital status, health status, financial dependency, and cultural traditions like kinship patterns and the social support available to the aged. This plays a major role in rehabilitation of the elderly with DSI.

A standardized definition for DSI for elderly is needed, to accurately assess the characteristics and develop policies. Relationships of single sensory impairments and their disability have been extensively studied, but the psychosocial and functional impacts of DSI are less well understood. Similar studies have to be planned on a larger population for better generalization. Hence further research is required in this aspect, enabling a better understanding of the special needs of this group and facilitating communication among providers to identify and improve healthcare outcomes. A significant consensus on advances in the care of the elderly was that in the past three decades there was "a wider appreciation that many of the illnesses and disabilities that were formerly considered inevitable in the elderly could now be regarded as remediable." This underscores the importance of providing appropriate health and medical care to the elderly.

\section{Conclusions}

Prevalence of visual impairment, hearing impairment, and DSI is high among rural elderly of India. Prevalence of high frequency hearing loss is higher among elderly warranting the need to include high frequency pure tones in classifying DSI among them. In view of high prevalence and association of adverse social factors, opportunistic screening of elderly attending regular health care has to be included. As elderly with DSI pose unique challenges in rehabilitation, a team approach including ophthalmologists and audiologists with mutual consensus is required at the community level. It is a wake-up call for developing countries like India to scale up primary health care services to diagnose and rehabilitate elderly in their community. 


\section{Conflict of Interests}

There were no funding sources. The authors declare that they have no Conflict of interests.

\section{Acknowledgment}

The authors would like to thank the Department of Community Health, St. John's Medical College for the support provided. Ramamurthy Deepthi was working as a Resident/Postgraduate Student at St. John's Medical College at the time of study and is now working at ESIC-MC \& PGIMSR as an Assistant Professor.

\section{References}

[1] M. Brennan, A. Horowitz, and Y.-P. Su, "Dual sensory loss and its impact on everyday competence," Gerontologist, vol. 45, no. 3, pp. 337-346, 2005.

[2] B. K. Keller, J. L. Morton, V. S. Thomas, and J. F. Potter, "The effect of visual and hearing impairments on functional status," Journal of the American Geriatrics Society, vol. 47, no. 11, pp. 1319-1325, 1999.

[3] J. E. Crews and V. A. Campbell, "Vision impairment and hearing loss among community-dwelling older Americans: implications for health and functioning," American Journal of Public Health, vol. 94, no. 5, pp. 823-829, 2004.

[4] T. Lupsakko, M. Mantyjarvi, H. Kautiainen, and R. Sulkava, "Combined hearing and visual impairment and depression in a population aged 75 years and older," International Journal of Geriatric Psychiatry, vol. 17, no. 9, pp. 808-813, 2002.

[5] E.-M. Chia, P. Mitchell, E. Rochtchina, S. Foran, M. Golding, and J. J. Wang, "Association between vision and hearing impairments and their combined effects on quality of life," Archives of Ophthalmology, vol. 124, no. 10, pp. 1465-1470, 2006.

[6] B. L. Lam, D. J. Lee, O. Gomez-Marin, D. D. Zheng, and A. J. Caban, "Concurrent visual and hearing impairment and risk of mortality: the National Health Interview Survey," Archives of Ophthalmology, vol. 124, no. 1, pp. 95-101, 2006.

[7] “Census of India 2011," 2013, http://censusindia.gov.in/Census_ And_You/age_structure_and_marital_status.aspx.

[8] M. Alam, K. S. James, G. Giridhar et al., "Building a knowledge base on population aging in India," Report on the Status of Elderly in Select States of India, United Nations Population Fund, Lodhi Estate, New Delhi, 2011.

[9] Government of India (GOI), Ministry of Social Justice Empowerment, Programmes for care of older persons, 1999, http://socialjustice.nic.in/faqs2.php\#q2.

[10] V. A. Campbell, J. E. Crews, D. G. Moriarty, M. M. Zack, and D. K. Blackman, "Surveillance for sensory impairment, activity limitation, and health-related quality of life among older adults-United States, 1993-1997," Morbidity and Mortality Weekly Report, vol. 48, no. 8, pp. 131-156, 1999.

[11] K.-L. Chou and I. Chi, "Combined effect of vision and hearing impairment on depression in elderly Chinese," International Journal of Geriatric Psychiatry, vol. 19, no. 9, pp. 825-832, 2004.

[12] S. L. Smith, L. W. Bennett, and R. H. Wilson, "Prevalence and characteristics of dual sensory impairment (hearing and vision) in a veteran population," Journal of Rehabilitation Research \& Development, vol. 45, no. 4, pp. 597-610, 2008.
[13] D. Lieberman, M. Friger, and D. Lieberman, "Visual and hearing impairment in elderly patients hospitalized for rehabilitation following hip fracture," Journal of Rehabilitation Research \& Development, vol. 41, no. 5, pp. 669-674, 2004.

[14] R. Deepthi and A. Kasthuri, "Visual and hearing impairment among rural elderly of south India: a community-based study," Geriatrics and Gerontology International, vol. 12, no. 1, pp. 116122, 2012.

[15] E. P. Fowler, "Hearing standards for acceptance, disability rating, and discharge in the military and in industry," Laryngoscope, vol. 51, no. 10, pp. 937-956, 1941.

[16] R. Carhart, "Speech reception in relation to pattern of pure tone loss," The Journal of Speech Disorders, vol. 11, pp. 97-108, 1946.

[17] J. D. Harris, "Pure tone acuity and the intelligibility of everyday speech," The Journal of the Acoustical Society of America, vol. 37, pp. 824-830, 1965.

[18] K. D. Kryter, C. Williams, and D. M. Green, "Auditory acuity and the perception of speech," Journal of the Acoustical Society of America, vol. 34, no. 9, pp. 1217-1223, 1962.

[19] R. H. Wilson and R. Mcardle, "Speech signals used to evaluate functional status of the auditory system," Journal of Rehabilitation Research \& Development, vol. 42, no. 4, supplement 2, pp. 79-94, 2005.

[20] S. Parasuraman, Role of Women's Education in Shaping Fertility in India: Evidences From National Family Health Survey, Himalaya Publishing House, Mumbai, India, 1999.

[21] T. W. Wong, T. S. Yu, W. Q. Chen, Y. L. Chiu, C. N. Wong, and A. H. S. Wong, "Agreement between hearing thresholds measured in non-soundproof work environments and a soundproof booth," Occupational and Environmental Medicine, vol. 60, no. 9, pp. 667-671, 2003.

[22] E. Chia, P. Mitchell, E. Rochtchina, S. Foran, M. Golding, and J. J. Wang, "Association between vision and hearing impairments and their combined effects on quality of life," Archives of Ophthalmology, vol. 124, no. 10, pp. 1465-1470, 2006.

[23] C. W. Klaver, C. W. Wolfs, J. R. Vingerling, A. Hofman, and P. T. de Jong, "Age-specific prevalence and causes of blindness and visual impairment in an older population: the Rotterdam study," Archives of Ophthalmology, vol. 116, no. 5, pp. 653-658, 1998.

[24] P. K. Nirmalan, R. D. Thulasiraj, V. Maneksha et al., "A population based eye survey of older adults in Tirunelveli district of South India: blindness, cataract surgery, and visual outcomes," British Journal of Ophthalmology, vol. 86, no. 5, pp. 505-512, 2002.

[25] A. L. Orr, Ed., Vision and Aging: Crossroads for Service Delivery, American Foundation for the Blind, New York, NY, USA, 1992.

[26] L. E. Glass, "Rehabilitation for deaf and hearing impaired elderly," in Aging and Rehabilitation: Advances in the State of the Art, S. J. Brody and G. E. Ruff, Eds., Springer, New York, NY, USA, 1986.

[27] H. L. Bate, "Hearing impairment among older people:a factor in communication," in Vision and Aging: Crossroads For Service Delivery, A. L. Orr, Ed., American Foundation for the Blind, New York, NY, USA, 1992.

[28] I. Appollonio, C. Carabellese, L. Frattola, and M. Trabucchi, "Effects of sensory aids on the quality of life and mortality of elderly people: a multivariate analysis," Age and Ageing, vol. 25, no. 2, pp. 89-96, 1996.

[29] C. D. Mulrow, C. Aguilar, J. E. Endicott et al., "Quality-of-life changes and hearing impairment. A randomized trial," Annals of Internal Medicine, vol. 113, no. 3, pp. 188-194, 1990. 
[30] W. B. Applegate, S. T. Miller, J. T. Elam, J. M. Freeman, T. O. Wood, and T. C. Gettlefinger, "Impact of cataract surgery with lens implantation on vision and physical function in elderly patients," Journal of the American Medical Association, vol. 257, no. 8, pp. 1064-1066, 1987. 


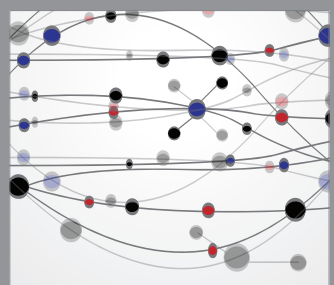

The Scientific World Journal
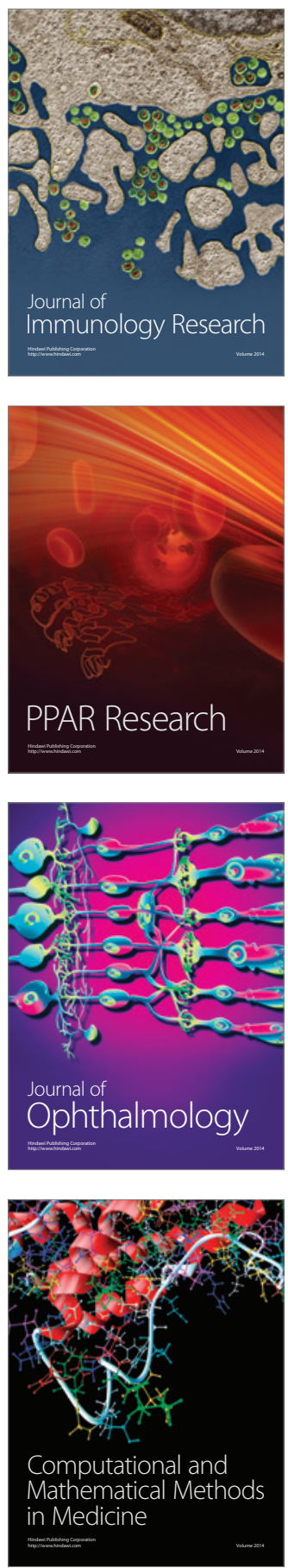

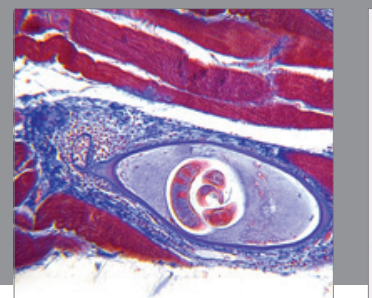

Gastroenterology

Research and Practice
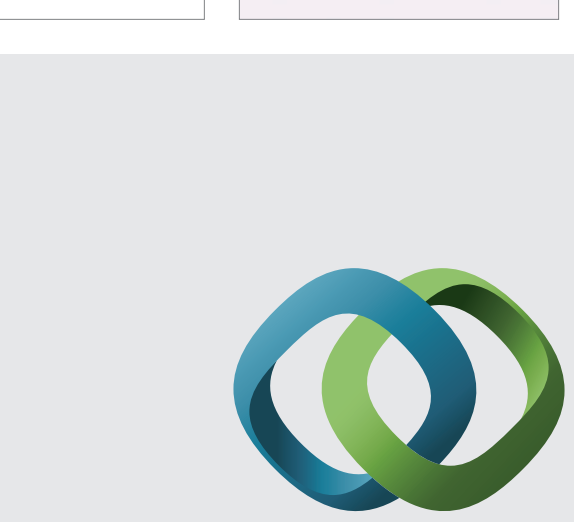

\section{Hindawi}

Submit your manuscripts at

http://www.hindawi.com
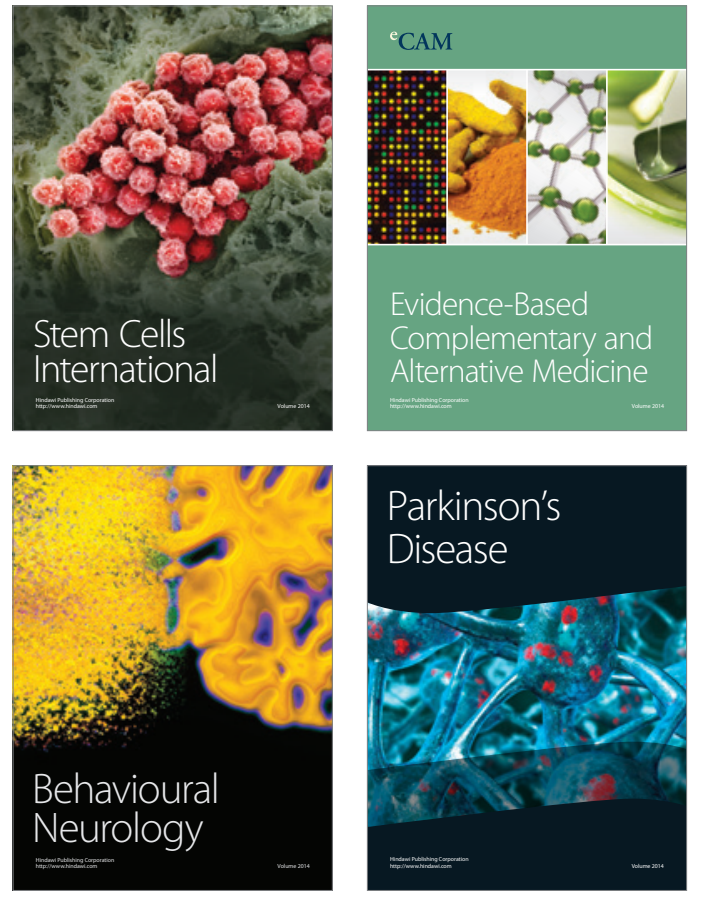
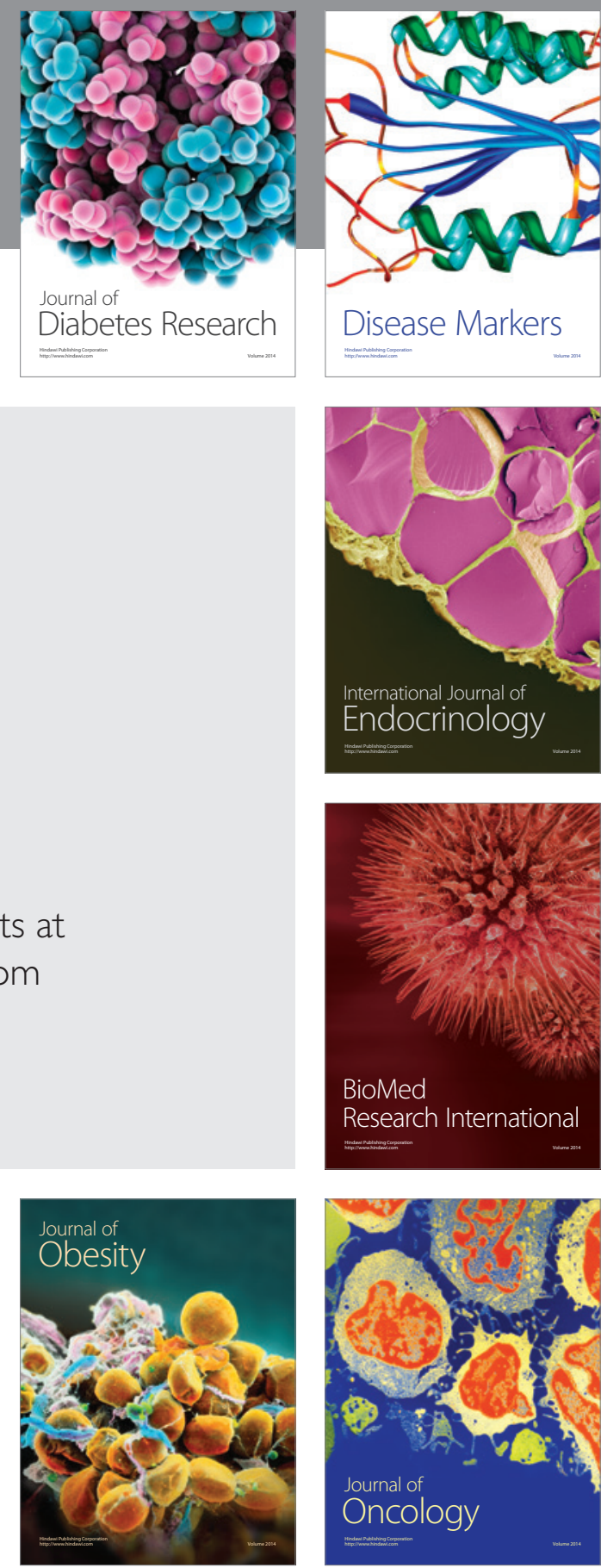

Disease Markers
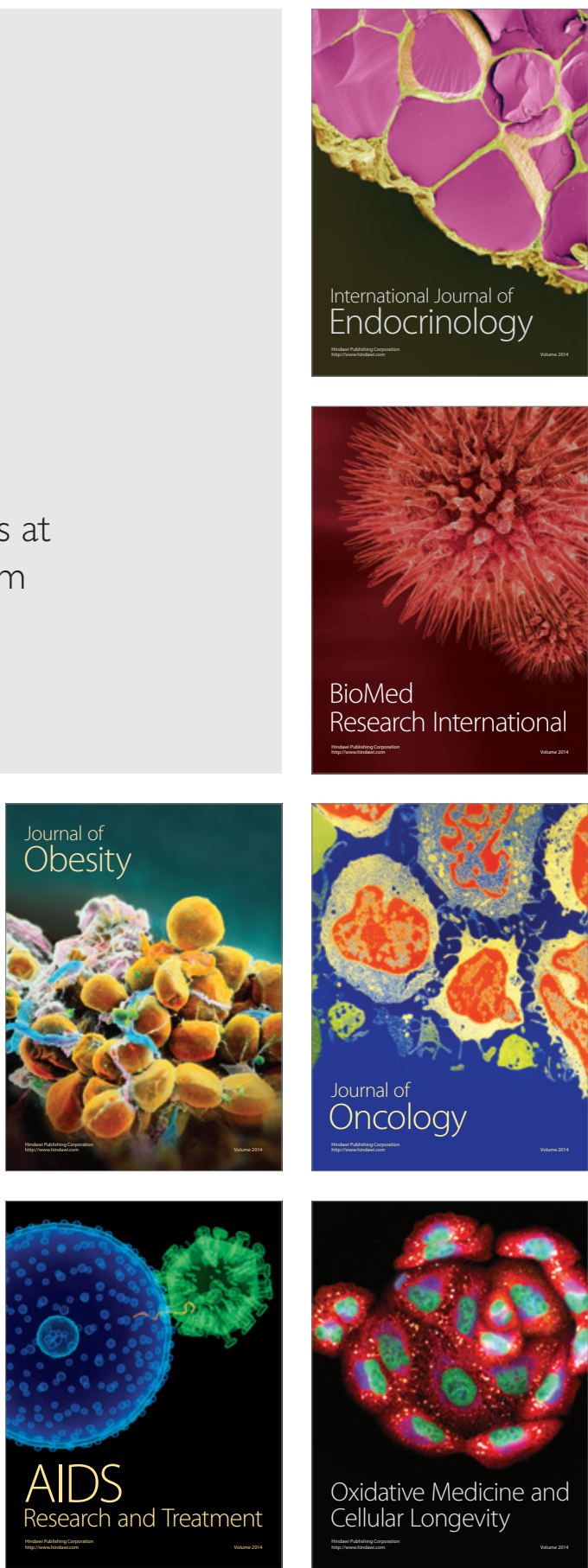